\title{
Mechanisms of nonsteroidal anti-inflammatory drug- induced gastrointestinal injury and repair: A window of opportunity for cyclooxygenase-inhibiting nitric oxide donors
}

\author{
Rafael Perini $M D^{1}$, Stefano Fiorucci $M D^{2}$, John L Wallace $\mathrm{PhD}^{1}$
}

\begin{abstract}
R Perini, S Fiorucci, JL Wallace. Mechanisms of nonsteroidal anti-inflammatory drug-induced gastrointestinal injury and repair: A window of opportunity for cyclooxygenase-inhibiting nitric oxide donors. Can J Gastroenterol 2004;18(4):229-236.

Nonsteroidal anti-inflammatory drugs (NSAIDs) cause damage in the upper gastrointestinal (GI) tract by impairing the ability of the mucosa to resist and respond to injury. Many of these effects of NSAIDs can be attributed to their ability to suppress mucosal prostaglandin synthesis. Selective inhibitors of cyclooxygenase (COX)-2 are less likely to disrupt mucosal defence and do not interfere with platelet aggregation. Thus, their use is associated with a reduced incidence of serious GI adverse events; however, a significant risk of such events still persists. At least in animal models, selective COX-2 inhibitors interfere with ulcer healing to the same extent as conventional NSAIDs. In contrast, COX-inhibiting nitric oxide donors (CINODs) produce anti-inflammatory and analgesic effects comparable or superior to those of NSAIDs, but with greatly reduced GI toxicity. Unlike NSAIDs and selective COX-2 inhibitors, CINODs do not interfere with ulcer healing. Moreover, because CINODs suppress the activity of both COX-1 and COX-2, they do not share with selective COX-2 inhibitors the lack of cardioprotection afforded by significant suppression of platelet aggregation. Because of their safety profile, CINODs may be particularly useful for long term prevention applications, such as for colon cancer, cardiovascular disease and Alzheimer's disease.
\end{abstract}

Key Words: Bleeding; COX; cyclooxygenase; Inflammation; Prostaglandin; Ulcer
Les mécanismes des lésions gastro-intestinales causées par des anti-inflammatoires non stéroïdiens et de leur réparation : Un créneau pour les donneurs de monoxyde d'azote inhibant la cyclo-oxygénase

\begin{abstract}
Les anti-inflammatoires non stéroïdiens (AINS) endommagent le tractus gastro-intestinal (GI) supérieur en altérant la capacité de la muqueuse à résister et à réagir aux lésions. Bien des effets des AINS à cet égard peuvent être attribués à leur capacité de supprimer la synthèse de la prostaglandine muqueuse. Les inhibiteurs sélectifs de la cyclo-oxygénase 2 (COX-2) sont moins susceptibles de perturber la défense muqueuse, et ils ne nuisent pas à l'agrégation plaquettaire. Par conséquent, leur usage s'associe à une diminution de l'incidence de graves effets GI secondaires, mais le risque de tels effets demeure marqué. Du moins chez les modèles animaux, les inhibiteurs sélectifs de la COX-2 nuisent à la cicatrisation des ulcères tout autant que les AINS conventionnels. Par contre, les donneurs de monoxyde d'azote inhibant la COX (DMAIC) produisent des effets anti-inflammatoires et analgésiques comparables ou supérieurs à ceux des AINS, mais leur toxicité GI est beaucoup plus faible. Contrairement aux AINS et aux inhibiteurs sélectifs de la COX-2, les DMAIC n'entravent pas la cicatrisation des ulcères. De plus, tandis qu'ils suppriment l'activité tant de la COX-1 que de la COX-2, les DMAIC ne partagent pas avec les inhibiteurs de la COX-2 cette absence de cardioprotection découlant de la suppression marquée de l'agrégation plaquettaire. En raison de leur profil d'innocuité, les DMAIC pourraient être particulièrement utiles dans des applications de prévention à long terme, dans des cas de cancer du côlon, de maladie cardiovasculaire ou de maladie d'Alzheimer, par exemple.
\end{abstract}

$\mathrm{N}^{\circ}$ onsteroidal anti-inflammatory drugs (NSAIDs) are commonly used to treat pain, inflammation and fever. However, their use is associated with a relatively high incidence of adverse reactions in the gastrointestinal (GI) tract $(1,2)$. Such damage can take the form of mucosal erosions or ulcers and can occur anywhere from the esophagus to the colon. In the small intestine, strictures can sometimes be found in chronic NSAID users. Of greatest concern from a clinical standpoint is the progression of ulcers to the point of perforation and the risk of severe bleeding from ulcers (1).
Gastric erosions are common (35\% to $60 \%$ of patients) and observed within a few hours of consumption of an NSAID. These lesions heal quite quickly and are generally regarded as being clinically insignificant. Ulcers are rare with fewer than six weeks of treatment with an NSAID, but their frequency increases linearly thereafter to $20 \%$ in six months $(3,4)$. It is possible that the true incidence and prevalence rates for ulcers are higher because the lesions are often asymptomatic (5). Of particular concern is the progression of NSAID-induced ulcers to the point where perforation or severe bleeding occurs, which is the case for $2 \%$ to $4 \%$ of chronic NSAID users (1).

\footnotetext{
${ }^{1}$ Mucosal Inflammation Research Group, University of Calgary, Calgary, Alberta; ${ }^{2}$ Department of Gastroenterology, University of Perugia, Perugia, Italy

Correspondence: Dr JL Wallace, Department of Pharmacology and Therapeutics, University of Calgary, 3330 Hospital Drive Northwest, Calgary, Alberta T2N 4N1. Telephone 403-220-4539, fax 403-270-3353, e-mail wallacej@ucalgary.ca

Received for publication December 3, 2003. Accepted February 12, 2004
} 
The incidence of intestinal lesions is more difficult to establish because these lesions often occur beyond the reach of an endoscope. However, it has been suggested that significant increases in intestinal permeability, significant bleeding and intestinal leukocyte accumulation occur in up to $70 \%$ of patients receiving long term NSAID therapy (6).

Whether there are different risks of ulceration with different NSAIDs has been a controversial subject, at least until recently $(7,8)$. With the introduction of a number of new NSAIDs in recent years (eg, meloxicam, nimesulide, etodolac, celecoxib, rofecoxib, valdecoxib), it has become clear that different NSAIDs do exhibit different risks for ulcer development. It has been suggested that these differences are related to the relative potency of these agents for inhibition of cyclooxygenase (COX)-1 (9). By sparing COX-1, these agents produce less suppression of mucosal prostaglandin (PG) synthesis, which, as described in more detail below, should result in less impairment of mucosal defence (10). Selective COX-2 inhibitors, such as rofecoxib and celecoxib, have been promoted as being as effective as conventional NSAIDs in terms of antiinflammatory and analgesic activities, while causing less GI injury. There is emerging evidence that challenges both aspects of these claims; that is, there is evidence that COX-1derived PGs contribute to the generation of pain and inflammation (11-14), that COX-2-derived PGs contribute to the resolution of inflammation $(11,15)$ and that COX-2-derived PGs contribute to mucosal defence (16-21). Selective COX-2 inhibitors also elicit additional adverse effects not seen with conventional NSAIDs, such as a propensity to increase the risk of myocardial infarction (22-24).

Improved GI safety profiles have also been reported for nitric oxide (NO)-releasing anti-inflammatory drugs, such as those in the new COX-inhibiting NO donor (CINOD) class (25-27). These agents are at least as effective as traditional NSAIDs (showing increased potency in some animal studies of analgesia) $(28,29)$ and have cardiovascular effects distinct from those of the selective COX-2 inhibitors (30-32). These cardiovascular effects are due to the fact that CINODs suppress COX-1 activity, thereby inhibiting platelet aggregation, and release $\mathrm{NO}$, which itself can inhibit platelet aggregation, inhibit leukocyte adherence to the vascular endothelium and attenuate vascular injury in many settings. Indeed, NO-releasing NSAIDs have been shown to have beneficial effects in animal models of hypertension, myocardial dysfunction and restenosis, in contrast to the behaviour of selective COX-2 inhibitors in these models (29-36).

The safety and efficacy of NO-releasing NSAIDs have recently been demonstrated in a number of phase I and phase II clinical trials. The results of several of these trials have yet to be published. However, two recent papers did report on the GI safety of NCX-4016, an NO-releasing derivative of aspirin $(37,38)$. Figure 1 shows some of the key data from one of those trials. Administration of acetylsalicylic acid (ASA) twice daily for eight days resulted in significant endoscopic damage to the stomach and duodenum (37). However, administration of NCX-4016, at equimolar doses, did not produce significant damage (ie, scores of the patients in the endoscopic group were not different from scores of those in the placebo group). Nevertheless, NCX-4016 produced suppression of platelet aggregation comparable to that seen with ASA. The observations that selective COX-2 inhibitors appear to increase the risk of myocardial infarction $(22-24)$ led to the suggestion by

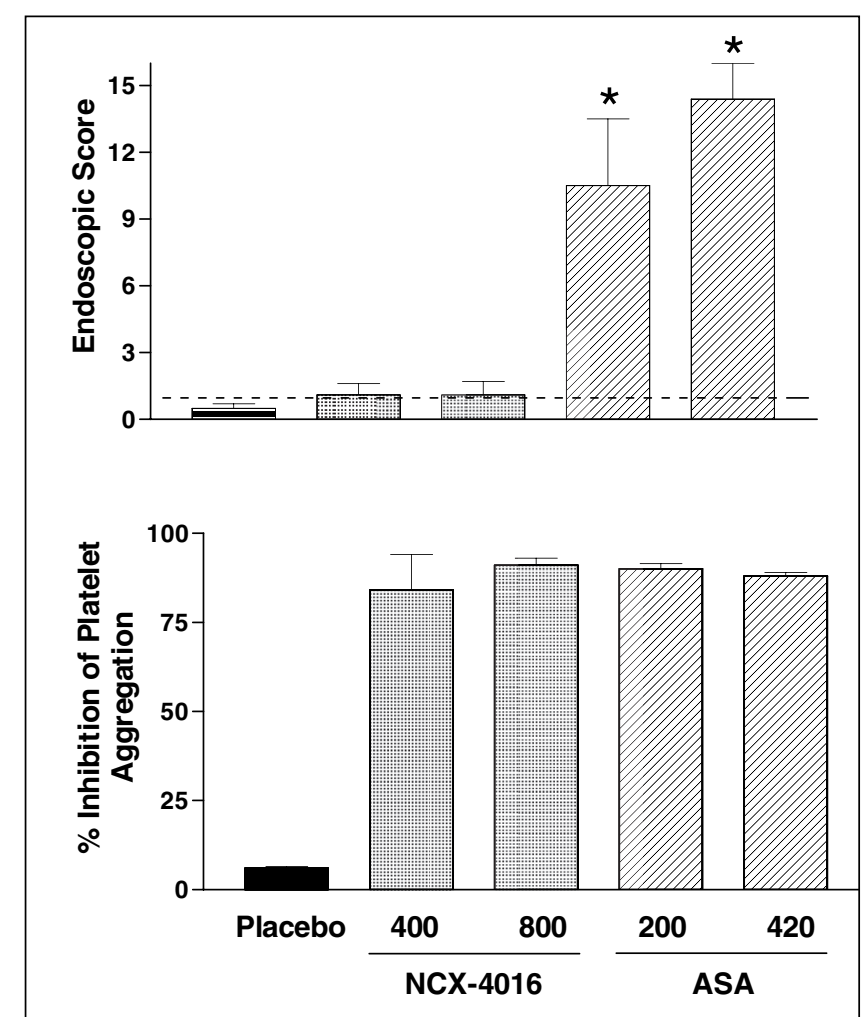

Figure 1) Top Endoscopic scoring of gastroduodenal damage in human volunteers taking placebo, acetylsalicylic acid (ASA) (200 mg or $420 \mathrm{mg}$ bid) or NCX-4016 (400 mg or $800 \mathrm{mg}$ twice daily) for 14 days. ${ }^{*} P<0.05$ versus the placebo group. The dotted line indicates two standard deviations above the mean for the placebo group. Bottom Percentage inhibition of arachidonate-induced platelet aggregation. Samples of platelets were prepared from blood taken from each of the volunteers on the final day of the study. Data from reference 37

some that these drugs should be taken together with low dose ASA in patients at risk of serious cardiovascular disease. However, a concern with this approach is that taking these two types of drugs together may cause significant gastric damage. Indeed, this is precisely what was observed in animal studies $(39,40)$. This prompted us to examine, in healthy volunteers, whether co-administration of low dose ASA and a selective COX-2 inhibitor would cause significant GI damage, and if the same degree of damage would be observed when NCX-4016 was substituted for ASA. As shown in Figure 2, celecoxib administration resulted in a significant increase in the extent of endoscopically detected gastroduodenal damage as compared with that induced by ASA alone (38). However, NCX-4016 did not produce significant damage when given alone or together with celecoxib.

\section{MECHANISMS OF NSAID-INDUCED INJURY}

The mechanisms responsible for NSAID-induced ulcerative lesions of the GI tract are not completely understood, particularly with respect to the lesions in the small intestine $(2,41,42)$. A number of possible etiological factors has been proposed, including direct toxic effects of these drugs on the epithelium, alterations in the mucosal microcirculation and impairment of normal repair processes. 


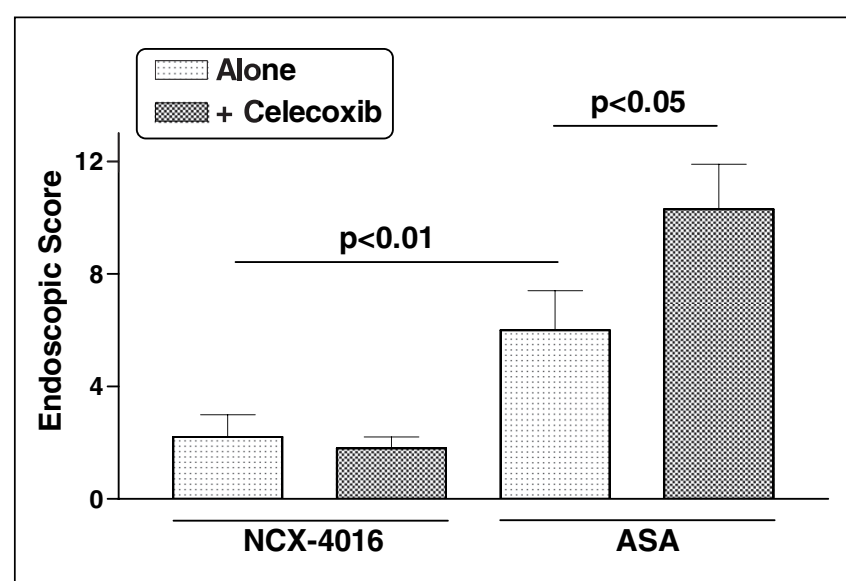

Figure 2) Endoscopic scores of gastroduodenal damage in human volunteers taking acetylsalicylic acid (ASA) (100 mg daily) or NCX4016 (800 mg twice daily) alone or together with celecoxib (200 mg twice daily). Celecoxib significantly exacerbated gastroduodenal damage caused by ASA, but with NCX-4016 the level of damage remained minimal. Data from reference 38

\section{Topical irritant properties}

Some NSAIDs, particularly those that are weak acids, produce epithelial damage at sites of contact with the GI mucosa (43). In locations where the mucosa is in contact with acid, the drugs behave in accordance with the $\mathrm{pH}$ partition hypothesis. In the presence of hydrogen ions, the drug becomes an uncharged, lipid-soluble compound capable of nonionic diffusion into the mucosal cells $(44,45)$. In the near neutral intracellular environment, re-ionization of the drug occurs, which can lead to osmotic swelling and lysis of the cells. These drugs may also uncouple mitochondrial respiration, leading to cell death (42). A higher prevalence of esophageal ulcers and strictures has been reported for patients taking NSAIDs $(46,47)$, which includes over-the-counter NSAIDs and low dose ASA (48). Topical injury seems to be related to the time of contact of the drug with the esophageal mucosa because most of the lesions are at the level of the aortic arch and above the lower esophageal sphincter, where the capsule's transit tends to be delayed. However, in an experimental model of acid- and pepsin-induced esophagitis in rabbits, both the topical exposure to acidified ASA and intravenous administration of ASA increased mucosal injury and mucosal barrier dysfunction compared with controls (49). This damage was significantly reduced by the administration of $\mathrm{PGE}_{2}$ before exposure to the acidified ASA (49). In the stomach, the topical irritant proprieties of NSAIDs may also be related to the ability of NSAIDs to decrease the hydrophobicity of the mucus gel layer in the stomach, which has been suggested to be a primary barrier to damage induced by acid (50). It is important to note that gastric mucosal injury can occur after parenteral or rectal administration of NSAIDs, or after their administration in a prodrug or enteric-coated form, suggesting that systemic, rather than topical, effects may be of more importance in the pathogenesis of NSAID-induced ulceration (51-56).

Topical irritant effects of NSAIDs appear to play a clearer role in the pathogenesis of small intestine damage, where the enterohepatic recirculation of NSAIDs increases the exposure of the intestinal epithelium to these drugs. Ligation of the bile duct prevents much of the damage that is normally observed

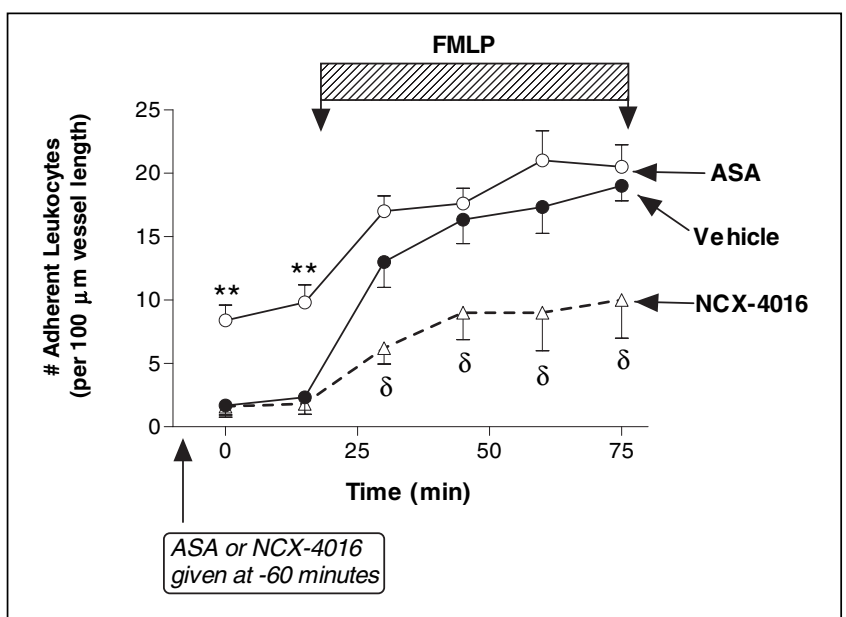

Figure 3) Leukocyte adherence to the vascular endothelium of rat mesenteric venules is stimulated by oral administration of acetylsalicylic acid (ASA), but not by nitric oxide (NO)-releasing ASA. Superfusion of the blood vessel (64) with a chemotactic peptide (fMLP; $5 \mu \mathrm{M})$ led to an increase in leukocyte adherence in vehicle-treated rats, and a further increase in leukocyte adherence in rats treated with ASA. In contrast, in rats treated $1 \mathrm{~h}$ before the experiment with a cyclooxygenase-inhibiting NO-donating drug, NCX-4016 (83 mg/kg by mouth), there was no effect on basal levels of leukocyte adherence (in contrast to results using an equimolar dose of ASA; $50 \mathrm{mg} / \mathrm{kg}$ by mouth), and the $\mathrm{MLP}$-induced leukocyte adherence was significantly reduced. NCX-4016 is an NO-releasing derivative of ASA (32). Each point represents the mean \pm SEM of at least five experiments. $* * P<0.05$ versus the control and NCX-4016 groups; $\delta P<0.05$ versus the ASA- and vehicle-treated groups

after NSAID administration in rats $(41,57)$. Chemical modification of diclofenac, such that it underwent significantly less enterohepatic recirculation, resulted in a marked attenuation of its ability to cause small intestinal damage (41). Moreover, such damage is not observed after administration of NSAIDs that do not undergo enterohepatic recirculation (41).

\section{Inhibition of PG synthesis}

The metabolism of arachidonic acid to PGs and leukotrienes is catalyzed by the COX and the 5-lipoxygenase enzyme pathways, respectively. In the gastric and duodenal mucosa, most arachidonic acid is converted into PGs of the $\mathrm{E}_{2}, \mathrm{~F}_{2 \alpha}$ and $\mathrm{I}_{2}$ subtypes. Perhaps the most important feature of NSAIDs that contributes to their ability to cause GI injury is the suppression of mucosal PG synthesis, by inhibiting the activity of COX $(10,58)$. Of course, inhibition of PG synthesis is also the mechanistic basis for many of the beneficial actions of NSAIDs. By suppressing mucosal PG synthesis, NSAIDs impair many of the key components of mucosal defence, including mucus formation and secretion, bicarbonate secretion and the protective $\mathrm{pH}$ gradient adjacent to the GI mucosa (10). Inhibition of mucosal PG synthesis also results in important changes in the GI microcirculation that appear to play crucial roles in the pathogenesis of ulceration (2).

\section{Decreased mucosal blood flow}

A high rate of blood flow to the luminal surface of the stomach is essential for mucosal defence. Acid back-diffusion into the mucosa can be tolerated so long as there is sufficient blood flow 


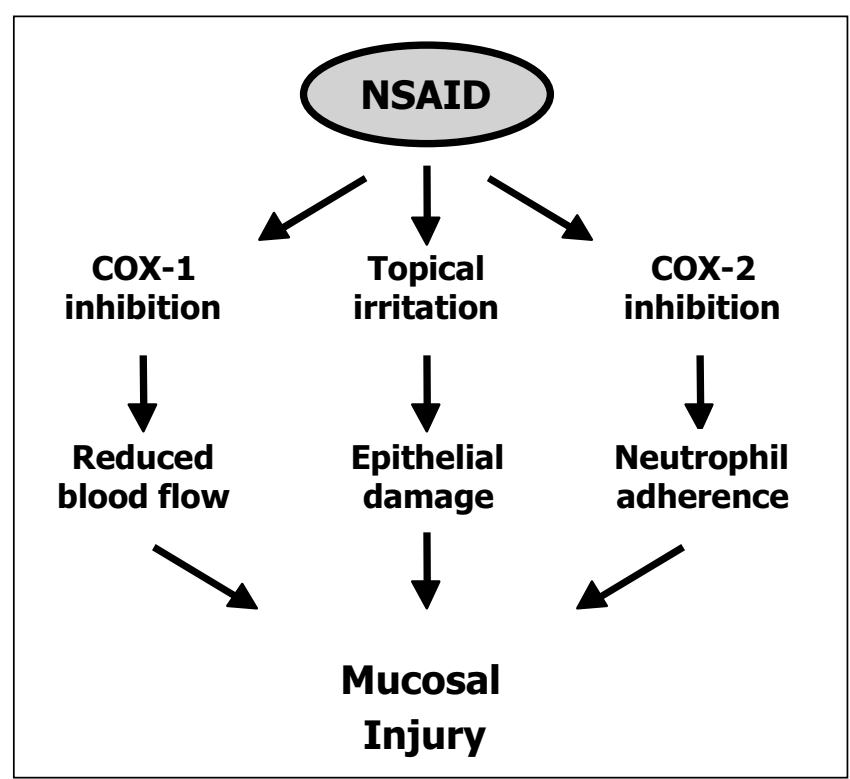

Figure 4) Nonsteroidal anti-inflammatory drug (NSAID)-induced mucosal injury occurs through at least three pathways. Suppression of cyclooxygenase (COX)-1 and COX-2 activity is essential for these lesions to form. In animal studies, suppression of COX-1 was shown to account for the reduction in gastric blood flow observed following NSAID administration (16). In contrast, suppression of COX-2 accounted for the induction of leukocyte adherence to the vascular endothelium observed following NSAID administration (16). Some NSAIDs, particularly those that are acidic, also have topical irritant properties that contribute to their ulcerogenicity (42)

to allow for buffering of the acid. When blood flow to the mucosa is decreased, the tissue becomes more susceptible to acid- and pepsin-induced damage. NSAIDs decrease mucosal blood flow to the stomach, but appear to do so in a 'patchy' manner. That is, blood flow is reduced at some foci in the stomach, but not at others. NSAID-induced lesions form predominantly at the sites of reduced mucosal blood flow (59). The reasons for this patchy distribution of blood are not clear. NSAID-induced inhibition of the synthesis of $\mathrm{PGE}_{2}$ and $\mathrm{PGI}_{2}$, which are vasodilators, is likely to be the underlying cause of the focal ischemia produced by these agents. Selective COX-2 inhibitors and CINODs do not reduce gastric mucosal blood flow $(16,26)$.

\section{Leukocyte activation}

NSAIDs can stimulate leukocytes, particularly neutrophils, such that they adhere to the vascular endothelium within the GI microcirculation $(60,61)$. A key role for neutrophils in the pathogenesis of NSAID-induced mucosal injury is supported by the observations that such damage is absent in neutropenic rats (62) and can be prevented by treatment of animals with neutralizing antibodies directed against leukocyte or endothelial adhesion molecules $(63,64)$. A role for neutrophils in the pathogenesis of NSAID-induced gastropathy was further supported by the observation that administration of PGs at doses previously shown to prevent gastric injury also prevented NSAID-induced leukocyte adherence $(60,61)$. Interestingly, in a human clinical trial of the use of famotidine for the prevention of NSAID-related gastroduodenal ulcers, the investigators reported that an increased peripheral white cell count correlated positively with the risk of ulcer development (65).
There are a number of mechanisms through which neutrophil adherence to the vascular endothelium could contribute to the pathogenesis of gastric mucosa injury. First, the factors that trigger the adherence of neutrophils to the vascular endothelium (such as leukotriene $\mathrm{B}_{4}$ and tumour necrosis factoralpha) also trigger the activation of these cells, leading to the liberation of oxygen-derived free radicals (eg, superoxide anion) and proteases (eg, elastase, collagenase). These substances may mediate much of the endothelial and epithelia 1 injury caused by NSAIDs. Indeed, NSAID-induced mucosal injury can be markedly reduced by scavengers of oxygenderived free radicals (66) and by inhibition of neutrophilderived proteases (67). Second, neutrophil adherence to the vascular endothelium could lead to obstruction of capillaries, resulting in reduced gastric mucosal blood flow. This wellcharacterized ability of NSAIDs to reduce gastric blood flow has been shown to occur subsequent to the appearance of "white thrombi" in the gastric microcirculation (68).

Selective COX-2 inhibitors share the feature of conventional NSAIDs of causing leukocyte adherence to the vascular endothelium (16,31). In contrast, CINODs do not cause leukocyte adherence (25). Indeed, these agents have been shown to inhibit leukocyte adherence caused by inflammatory mediators (69) (Figure 3) which could contribute to their broader spectrum of anti-inflammatory and analgesic activity as compared with conventional NSAIDs $(28,69)$.

\section{COX isoforms}

In connection with NSAID-induced GI mucosal damage, much research has recently been concentrated on the two known isoforms of COX. COX-1 is constitutively expressed throughout the GI tract (70). COX-2 is expressed at low levels in the GI tract, but can be rapidly induced in response to a number of factors. For example, COX-2 is rapidly induced in the stomach following administration of ASA (71). Recently a third isoform, COX-3, was described, and it was suggested that this isoform is susceptible to inhibition by acetaminophen (72). This enzyme is a splice variant of COX-1. Its role, if any, in GI mucosal defence has yet to be determined.

Therapeutic doses of conventional NSAIDs inhibit both COX-1 and COX-2 (9). There has been widespread speculation, including that by marketers of selective COX-2 inhibitors, that GI mucosal ulceration occurs predominantly because of inhibition of COX-1 (73). NSAIDs that selectively inhibit COX-2 (ie, that spare COX-1 at therapeutic doses) have been promoted on the basis that they cause less GI injury $(73,74)$. However, large outcomes studies of celecoxib and rofecoxib have indicated that these agents still produce significant GI injury, and their use is associated with a reduction of about $50 \%$ of GI bleeds $(22,74)$. Indeed, the incidence of serious GI adverse events with celecoxib did not differ significantly from that observed in patients taking one of two conventional NSAIDs (diclofenac and ibuprofen) (75). Concomitant use of low dose ASA appears to abrogate any benefit, in terms of GI injury, that is gained by taking a selective COX-2 inhibitor rather than a conventional NSAID (74). As outlined above, a recent study demonstrated, in healthy human volunteers, that administration of a selective COX-2 inhibitor significantly augmented the gastroduodenal injury caused by low dose ASA (38).

The relative contribution of inhibition of COX-1 versus COX-2 to NSAID-induced gastric mucosal injury was recently evaluated in the authors' laboratory (16) (Figure 4). The 
reduction of gastric blood flow that one observes following NSAID administration is attributable to suppression of COX-1. On the other hand, it is the inhibition of COX-2 by NSAIDs that accounts for leukocyte adherence within the GI microcirculation. Selective inhibition of COX-1 or of COX-2 does not result in gastric damage in the rat. Rather, combined inhibition of both isoforms of COX is necessary for mucosal damage to be observed (16). This observation has now been confirmed by another laboratory and extended to NSAID-induced small intestinal injury $(18,76)$.

\section{MECHANISMS OF MUCOSAL REPAIR}

The processes involved in wound healing, and specifically in the healing of mucosal wounds and ulcers, are not completely understood. Damage to the GI tract likely occurs on a daily basis, but ulcers only rarely develop (77). This is because breaks in the epithelial lining are rapidly repaired through a process known as "restitution" (78). Restitution involves migration of healthy epithelial cells from the gastric pits over the area that has been denuded. This occurs very rapidly. In experimental models, a completely denuded gastric epithelium can be re-epithelialized within $15 \mathrm{~min}$. The process occurs without need for cell division. Restitution requires there to be an undamaged basement membrane because this serves as the template along which the healthy epithelial cells migrate (79). In the presence of significant amounts of luminal acid, which can damage the basement membrane, restitution also requires the formation of a microenvironment over the site of damage in which the $\mathrm{pH}$ is relatively high (ie, close to neutral) (80). This "mucoid cap" is composed of mucus, fibrin and cellular debris. The maintenance of an appropriate $\mathrm{pH}$ within the mucoid cap is dependent upon uninterrupted blood flow to the mucosa.

When damage penetrates deeper into the mucosa, complete repair involves cell proliferation and re-establishment of the glandular architecture. If the damage does not penetrate the muscularis mucosae (which separates the mucosa from the submucosa), such repair can be achieved within one to three days. However, if the damage penetrates through the muscularis mucosa, a true "ulcer" is formed, and repair can take from weeks to months. Such repair involves the re-establishment of the vasculature, which involves new blood vessel growth (angiogenesis), re-establishment of glandular architecture and re-establishment of the mucosal immune system in the affected region. There is strong evidence for the involvement of a number of growth factors, including epidermal growth factor and vascular endothelial growth factor, in the process of ulcer repair $(81,82)$. Moreover, there can be upregulation of the receptors for some of these growth factors at the ulcer site (83). Interesting, platelets seem to play in important role in ulcer healing outside of their contribution to hemostasis (84). Platelets contain a wide array of growth factors and can deliver those growth factors to a site of tissue injury. Drugs that affect the content of growth factors within the platelet may thereby affect rates of ulcer healing.

COX-2 is also expressed by cells at the margin of ulcers, which is a key site for epithelial cell proliferation (85). As discussed below, PGs derived from COX-2 play an important role in ulcer healing and in the process of angiogenesis $(86,87)$.

\section{INFLUENCE OF NSAIDS ON ULCER HEALING}

NSAIDs can interfere with various aspects of mucosal repair. The rapid restitution that occurs through cell migration

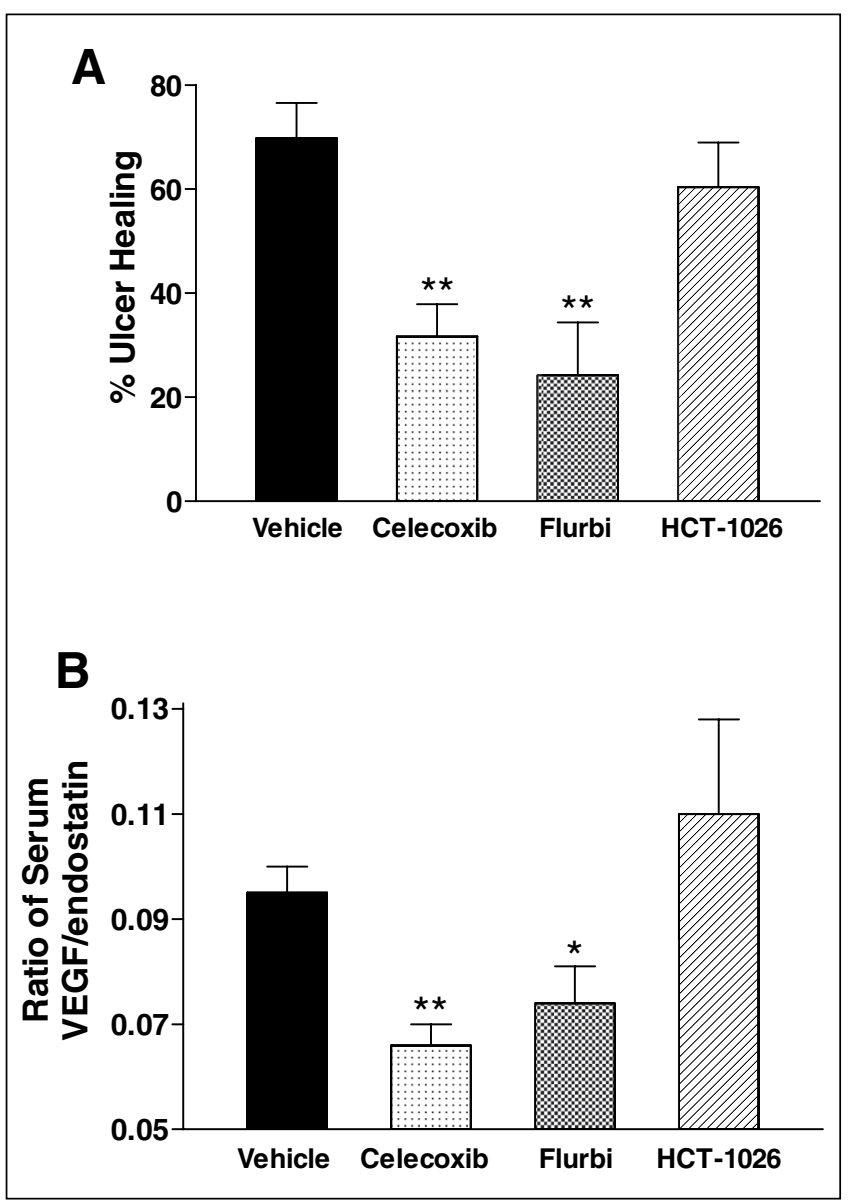

Figure 5) Effects of daily treatment with celecoxib, flurbiprofen (Flurbi) or a nitric oxide-releasing flurbiprofen derivative (HCT-1026) on gastric ulcer healing (A) and serum levels (B) of vascular endothelial growth factor (VEGF) and endostatin. The latter data are presented as a ratio of one to the other; VEGF is a potent pro-angiogenic factor, while endostatin is a potent anti-angiogenic factor. Celecoxib and flurbiprofen significantly impaired gastric ulcer healing and caused a significant shift in serum levels of VEGF versus endostatin. In contrast, HCT-1026 did not interfere with ulcer healing or cause a shift in the ratio of pro- to antiangiogenic factors. $* P<0.05, * * P<0.01$ versus the corresponding vehicle-treated group. Data from reference 90

following damage to the superficial epithelium of the stomach can be significantly impaired by NSAIDs. NSAIDs appear to rapidly dissipate the near neutral microenvironment within the mucoid cap over sites of damage. This is likely a consequence of inhibition of PG synthesis, which results in reduced mucosal blood flow (the $\mathrm{pH}$ within the mucoid cap is kept at near neutral by a continuous supply of plasma). NSAIDs can also reduce rates of epithelial turnover in the GI tract and interfere with angiogenesis (86). These actions likely contribute to the ability of NSAIDs to impair ulcer healing $(88,89)$. This adverse effect of NSAIDs can be overcome by using powerful inhibitors of gastric acid secretion, such as proton pump inhibitors (88). As mentioned above, COX-2 is expressed by epithelial cells at the margins of ulcers (85). Perhaps not surprisingly, selective COX-2 inhibitors delay gastric ulcer healing $(85,90)$. This action may be in part related to effects of these drugs on serum 
levels of growth factors that regulate angiogenesis. Treatment of rats with a selective COX-2 inhibitor (celecoxib) was found to alter the balance of pro- and anti-angiogenic factors in serum, resulting in a shift in the 'angiogenic balance' towards inhibition of angiogenesis (90). A conventional NSAID, flurbiprofen, produced the same effect (Figure 5). Moreover, both celecoxib and flurbiprofen significantly inhibited ulcer repair in this model. In contrast, when a NO-releasing derivative of flurbiprofen was given in the same manner, the balance of angiogenic factors in serum was not altered and this compound did not interfere with ulcer healing. In another study, a NO-releasing derivative of diclofenac was found to accelerate ulcer healing relative to a group treated with vehicle (91).

Selective COX-2 inhibitors also interfere with healing in other parts of the GI tract, and have been reported to exacerbate experimental colitis (21) and human inflammatory bowel disease (92). In contrast, agents in the CINOD class, which offer a multifactorial mechanism of action involving $\mathrm{NO}$

\section{REFERENCES}

1. Soll AH, Weinstein WM, Kurata J, McCarthy D. Nonsteroidal antiinflammatory drugs and peptic ulcer disease. Ann Intern Med 1991:114:307-19.

2. Wallace JL. Nonsteroidal anti-inflammatory drugs and gastroenteropathy: The second hundred years. Gastroenterology 1997;112:1000-16.

3. Kurata JH, Abbey DE. The effect of chronic aspirin use on duodenal and gastric ulcer hospitalizations. J Clin Gastroenterol 1990;12:260-6.

4. Geis GS, Stead H, Wallemark CB, Nicholson PA. Prevalence of mucosal lesions in the stomach and duodenum due to chronic use of NSAID in patients with rheumatoid arthritis or osteoarthritis, and interim report on prevention by misoprostol of diclofenac associated lesions. J Rheumatol 1991;28:11-4.

5. Pounder R. Silent peptic ulceration: Deadly silence or golden silence? Gastroenterology 1989;96:626-31.

6. Bjarnason I, Hayllar J, MacPherson AJ, Russell AS. Side effects of nonsteroidal anti-inflammatory drugs on the small and large intestine in humans. Gastroenterol 1993;104:1832-47.

7. Taragin MI, Carson JL, Strom BL. Gastrointestinal side effects of the nonsteroidal anti-inflammatory drugs. Dig Dis 1990;8:269-80.

8. Langman MJ, Weil J, Wainwright P, et al. Risks of bleeding peptic ulcer associated with individual non-steroidal anti-inflammatory drugs. Lancet 1994;343:1075-8.

9. Warner TD, Giuliano F, Vojnovic I, Bukasa A, Mitchell JA, Vane JR. Nonsteroid drug selectivities for cyclo-oxygenase- 1 rather than cyclooxygenase- 2 are associated with human gastrointestinal toxicity: a full in vitro analysis. Proc Natl Acad Sci USA 1999;96:7563-8.

10. Wallace JL, Tigley AW. Review article: New insights into prostaglandins and mucosal defence. Aliment Pharmacol Ther 1995;9:227-35.

11. Wallace JL, Bak A, McKnight W, Asfaha S, Sharkey KA, MacNaughton WK. Cyclooxygenase 1 contributes to inflammatory responses in rats and mice: Implications for gastrointestinal toxicity. Gastroenterology 1998;115:101-9.

12. Gretzer B, Knorth H, Chantrain M, et al. Effects of diclofenac and L-745,337, a selective cyclooxygenase- 2 inhibitor, on prostaglandin $\mathrm{E}_{2}$ formation in tissue from human colonic mucosa and chronic bursitis. Gastroenterology 1998;114:A139.

13. Wallace JL, Chapman K, McKnight W. Limited anti-inflammatory efficacy of cyclooxygenase-2 inhibition in carrageenan-airpouch inflammation. Br J Pharmacol 1999;126:1200-5.

14. Tegeder I, Niederberger E, Vetter G, Brautigam L, Geisslinger G. Effects of selective COX-1 and - 2 inhibition on formalin-evoked nociceptive behaviour and prostaglandin $\mathrm{E}_{2}$ release in the spinal cord. J Neurochem 2001;79:777-86.

15. Gilroy DW, Tomlinson A, Willoughby DA. Differential effects of inhibition of isoforms of cyclooxygenase (COX-1, COX-2) in chronic inflammation. Inflamm Res 1998;47:79-85. release and COX inhibition, do not interfere with ulcer healing and do not exacerbate colitis $(91,93)$.

\section{CONCLUSIONS}

NSAIDs cause GI mucosal damage by disrupting protective factors and by interfering with the healing of mucosal ulcers. Selective inhibitors of COX-2 are less likely to disrupt mucosal defence, but appear to cause the same degree of inhibition of ulcer healing as is seen with conventional NSAIDs. In contrast, CINODs produce anti-inflammatory and analgesic effects comparable or superior to those of NSAIDs, but with greatly reduced GI toxicity. Unlike NSAIDs and selective COX-2 inhibitors, CINODs do not interfere with ulcer healing. Moreover, the inhibition of platelet aggregation and the many other beneficial effects of $\mathrm{NO}$ in the microcirculation make CINODs an attractive option for cardioprotective indications, or for use in patients where cardioprotection is warranted.

16. Wallace JL, McKnight W, Reuter BK, Vergnolle N. NSAID-induced gastric damage in rats: Requirement for inhibition of both cyclooxygenase 1 and 2. Gastroenterology 2000;119:706-14.

17. Gretzer B, Ehrlich K, Maricic N, Lambrecht N, Respondek M, Peskar BM. Selective cyclo-oxygense- 2 inhibitors and their influence on the protective effect of a mild irritant in the rat stomach. Br J Pharmacol 1998;123:927-35.

18. Gretzer B, Maricic N, Respondek M, Schuligoi R, Peskar BM. Effects of specific inhibition of cyclo-oxygenase- 1 and cyclo-oxygenase- 2 in the rat stomach with normal mucosa and after acid challenge. Br J Pharmacol 2001;132:1565-73.

19. Maricic N, Ehrlich K, Gretzer B, Schuligoi R, Respondek M, Peskar BM. Selective cyclo-oxygenase-2 inhibitors aggravate ischaemiareperfusion injury in the rat stomach. Br J Pharmacol 1999; $128: 1659-66$.

20. Tanaka A, Hase S, Miyazawa T, Takeuchi K. Up-regulation of cyclooxygenase- 2 by inhibition of cyclooxygenase-1: A key to nonsteroidal anti-inflammatory drug-induced intestinal damage. J Pharmacol Exp Ther 2002;300:754-61.

21. Reuter BK, Asfaha S, Buret A, Sharkey KA, Wallace JL. Exacerbation of inflammation-associated colonic injury in rat through inhibition of cyclooxygenase-2. J Clin Invest 1996;98:2076-85.

22. Bombardier C, Laine L, Reicin A, et al. Comparison of upper gastrointestinal toxicity of rofecoxib and naproxen in patients with rheumatoid arthritis. VIGOR Study Group. N Engl J Med 2000;343:1520-8

23. Ray WA, Stein CM, Daugherty JR, Hall K, Arbogast PG, Griffin MR. COX-2 selective non-steroidal anti-inflammatory drugs and risk of serious coronary heart disease. Lancet 2002;360:1071-3.

24. Fitzgerald GA. COX-2 and beyond: Approaches to prostaglandin inhibition in human disease. Nature Reviews Drug Discov 2003;2:879-90.

25. Wallace JL, Reuter B, Cicala C, McKnight W, Grisham MB, Cirino G. Novel nonsteroidal anti-inflammatory drug derivatives with markedly reduced ulcerogenic properties in the rat. Gastroenterology 1994;107:173-9.

26. Wallace JL, Reuter B, Cicala C, McKnight W, Grisham M, Cirino G. A diclofenac derivative without ulcerogenic properties. Eur J Pharmacol 1994;257:249-55.

27. Wallace JL, Elliott SN, Del Soldato P, McKnight W, Sannicolo F, Cirino G. Gastrointestinal sparing anti-inflammatory drugs: The development of nitric oxide-relasing NSAIDs. Drug Develop Res 1997;42:144-9.

28. Davies NM, Roseth AG, Appleyard CB, et al. NO-naproxen vs. naproxen: Ulcerogenic, analgesic and anti-inflammatory effects. Aliment Pharmacol Ther 1997;11:69-79.

29. Wallace JL, McKnight W, Del Soldato P, Baydoun AR, Cirino G. Anti-thrombotic effects of a nitric oxide-releasing, gastric-sparing aspirin derivative. J Clin Invest 1995;96:2711-8. 
30. Muscara MN, McKnight W, Lovren F, Triggle CR, Cirino G, Wallace JL. Antihypertensive properties of a nitric oxide-releasing naproxen derivative in two-kidney, one-clip rats. Am J Physiol 2000;279:H528-35.

31. Muscara MN, Vergnolle N, Lovren F, et al. Selective cyclooxygenase- 2 inhibition with celecoxib elevates blood pressure and promotes leukocyte adherence. Br J Pharmacol 2000;129:1423-30.

32. Muscara MN, Lovren F, McKnight W, et al. Vasorelaxant effects of a nitric oxide-releasing aspirin derivative in normotensive and hypertensive rats. Br J Pharmacol 2001;133:1314-22.

33. Napoli C, Cirino G, Del Soldato P, et al. Effects of nitric oxidereleasing aspirin versus aspirin on restenosis in hypercholesterolemic mice. Proc Natl Acad Sci USA 2001;98:2860-4.

34. Yu J, Rudic RD, Sessa WC. Nitric oxide-releasing aspirin decreases vascular injury by reducing inflammation and promoting apoptosis. Lab Invest 2002;82:825-32.

35. Napoli C, Aldini G, Wallace JL, et al. Efficacy and age-related effects of nitric oxide-releasing aspirin on experimental restenosis. Proc Natl Acad Sci USA 2002;99:1689-94.

36. Napoli C, Ackah E, De Nigris F, et al. Chronic treatment with nitric oxide-releasing aspirin reduces plasma low-density lipoprotein oxidation and oxidative stress, arterial oxidation-specific epitopes, and atherogenesis in hypercholesterolemic mice. Proc Natl Acad Sci USA 2002;99:12467-70.

37. Fiorucci S, Santucci L, Gresele P, Faccino RM, Del Soldato P, Morelli A. Gastrointestinal safety of NO-aspirin (NCX-4016) in healthy human volunteers: a proof of concept endoscopic study. Gastroenterology 2003;124:600-7.

38. Fiorucci S, Santucci L, Wallace JL, et al. Interaction of a selective cyclooxygenase- 2 inhibitor with aspirin and NO-releasing aspirin in the human gastric mucosa. Proc Natl Acad Sci USA 2003;100:10937-41.

39. Fiorucci S, de Lima OM Jr, Mencarelli A, et al. Cyclooxygenase-2derived lipoxin $\mathrm{A}_{4}$ increases gastric resistance to aspirin-induced damage. Gastroenterology 2002;123:1598-606.

40. Wallace JL, McKnight W, Dicay M, Mencarelli A, del Soldato P, Fiorucci S. Aspirin, but not NO-releasing aspirin (NCX-4016), interacts with selective COX-2 inhibitors to aggravate gastric damage and inflammation. Am J Physiol 2004;286:G76-81.

41. Reuter BK, Davies NM, Wallace JL. Nonsteroidal antiinflammatory drug enteropathy in rats: Role of permeability, bacteria, and enterohepatic circulation. Gastroenterology 1997;112:109-17.

42. Somasundaram S, Sigthorsson G, Simpson RJ, et al. Uncoupling of intestinal mitochondrial oxidative phosphorylation and inhibition of cyclooxygenase are required for the development of NSAIDenteropathy in the rat. Aliment Pharmacol Ther 2000;14:639-50.

43. Lichtenberger LM. Where is the evidence that cyclooxygenase inhibition is the primary cause of nonsteroidal anti-inflammatory drug (NSAID)-induced gastrointestinal injury? Topical injury revisited. Biochem Pharmacol 2001;61:631-7.

44. Hogben CAM, Schanker LS, Tocco DJ. Absorption of drugs from the stomach. II. The human. J Pharmacol Exp Ther 1957;129:540-5.

45. McCormack K, Brune K. Classical absorption theory and the development of gastric mucosal damage associated with the nonsteroidal anti-inflammatory drugs. Arch Tox 1987;60:261-9.

46. Shallcross TM, Wyatt JI, Rathbone BJ, Heatley RV. Non-steroidal anti-inflammatory drugs, hiatus hernia, and Helicobacter pylori, in patients with oesophageal ulceration. Br J Rheumatol 1990;29:288-90.

47. Minocha A, Greenbaum DS. Pill-esophagitis caused by nonsteroidal antiinflammatory drugs. Am J Gastroenterol 1991;86:1086-9.

48. Kim SL, Hunter JG, Wo JM, Davis LP, Waring JP. NSAIDs, aspirin, and esophageal strictures: Are over-the-counter medications harmful to the esophagus? J Clin Gastroenterol 1999;29:32-4.

49. Lanas AI, Sousa FL, Ortego J, et al. Aspirin renders the oesophageal mucosa more permeable to acid and pepsin. Eur J Gastroenterol Hepatol 1995; 7:1065-72.

50. Lichtenberger LM. The hydrophobic barrier properties of gastrointestinal mucus. Annu Rev Physiol 1995;57:565-83.

51. Estes LL, Fuhs DW, Heaton AH, Butwinick CS. Gastric ulcer perforation, associated with the use of injectable ketorolac. Ann Pharmacother 1993;27:42-3.
52. Henry D, Dobson A, Turner C. Variability in the risk of major gastrointestinal complications from nonaspirin nonsteroidal antiinflammatory drugs. Gastroenterology 1993;10:1078-88.

53. Wallace JL, McKnight GW. Characterization of a simple animal model for nonsteroidal anti-inflammatory drug induced antral ulcer. Can J Physiol Pharmacol 1993;71:447-52.

54. Graham DY, Smith JL, Holmes GI, Davies RO. Nonsteroidal antiinflammatory effect of sulindac sulfoxide and sulfide on gastric mucosa. Clin Pharmacol Ther 1985;38:65-70.

55. Carson JL, Strom BL, Soper KA, West SL, Morse L. The relative gastrointestinal toxicity of the nonsteroidal anti-inflammatory drugs. Arch Intern Med 1987;147:1054-9.

56. Hawthorne AB, Mahida YR, Cole AT, Hawkey CJ. Aspirininduced gastric mucosal damage: Prevention by enteric-coating and relation to prostaglandin synthesis. Br J Clin Pharmacol 1991;32:7-83.

57. Wax J, Clinger WA, Varner P, Bass P, Winder CV. Relationship of the enterohepatic cycle to ulcerogenesis in the rat small bowel with flufenamic acid. Gastroenterology 1970;58:772-80.

58. Vane JR. Inhibition of prostaglandin synthesis as a mechanism of action for aspirin-like drugs. Nature New Biol 1971;231:232-5.

59. Gana TJ, Huhlewych R, Koo L. Focal gastric mucosal blood flow in aspirin-induced ulceration. Ann Surg 1987;205:399-403.

60. Asako H, Kubes P, Wallace JL, Gaginella T, Wolf RE, Granger DN. Indomethacin-induced leukocyte adhesion in mesenteric venules: Role of lipoxygenase products. Am J Physiol 1992;262:G903-8.

61. Asako H, Kubes P, Wallace JL, Wolf RE, Granger DN. Modulation of leukocyte adhesion to rat mesenteric venules by aspirin and salicylate. Gastroenterology 1992;103:146-52.

62. Wallace JL, Keenan CM, Granger DN. Gastric ulceration induced by nonsteroidal anti-inflammatory drugs is a neutrophil-dependent process. Am J Physiol 1990;259:G462-7.

63. Wallace JL, Arfors K-E, McKnight GW. A monoclonal antibody against the CD18 leukocyte adhesion molecule prevents indomethacin-induced gastric damage in the rabbit. Gastroenterology 1991;100:878-83.

64. Wallace JL, McKnight W, Miyasaka M, et al. Role of endothelial adhesion molecules in NSAID-induced gastric mucosal injury. Am J Physiol 1993;265:G993-8.

65. Taha AS, Hudson N, Hawkey CJ, et al. Famotidine for the prevention of gastric and duodenal ulcers caused by nonsteroidal antiinflammatory drugs. N Engl J Med 1996;334:1435-9.

66. Del Soldato P, Foschi D, Benoni G, Scarpignato C. Oxygen free radicals interact with indomethacin to cause gastrointestinal injury. Agents Actions 1986;17:484-8.

67. Vaananen PM, Meddings JB, Wallace JL. Role of oxygen-derived free radicals in indomethacin-induced gastric injury. Am J Physiol 1991;261:G470-5.

68. Kitahora T, Guth PH. Effect of aspirin plus hydrochloric acid on the gastric mucosal microcirculation. Gastroenterology 1987;93:810-7.

69. Wallace JL, Vergnolle N, Muscara MN, et al. Enhanced antiinflammatory effects of a nitric oxide-releasing derivative of mesalamine in rats. Gastroenterology 1999;117:557-66.

70. Kargman S, Charleson S, Cartwright M, et al. Characterization of prostaglandin $\mathrm{G} / \mathrm{H}$ synthase 1 and 2 in rat, dog, monkey, and human gastrointestinal tracts. Gastroenterology 1996;111:445-54.

71. Davies NM, Sharkey KA, Asfaha S, MacNaughton WK, Wallace JL. Aspirin induces a rapid up-regulation of cyclooxygenase-2 expression in the rat stomach. Aliment Pharmacol Ther 1997;11:1101-8.

72. Hawkey CJ. COX-2 inhibitors. Lancet 1999;353:307-14.

73. Laine L, Harper S, Simon T, et al. A randomized trial comparing the effect of rofecoxib, a cyclooxygenase 2-specific inhibitor, with that of ibuprofen on the gastroduodenal mucosa of patients with osteoarthritis. Rofecoxib Osteoarthritis Endoscopy Study Group. Gastroenterology 1999;117:776-83.

74. Silverstein FE, Faich G, Goldstein JL, et al. Gastrointestinal toxicity with celecoxib vs nonsteroidal anti-inflammatory drugs for osteoarthritis and rheumatoid arthritis: the CLASS study: A randomized controlled trial. Celecoxib Long-term Arthritis Safety Study. JAMA 2000;284:1247-55.

75. Juni P, Rutjes AW, Dieppe PA. Are selective COX 2 inhibitors superior to traditional non steroidal anti-inflammatory drugs? Br Med J 2002;324:1287-8. 
76. Tanaka A, Hase S, Miyazawa T, Takeuchi K. Up-regulation of cyclooxygenase-2 by inhibition of cyclooxygenase-1: a key to nonsteroidal anti-inflammatory drug-induced intestinal damage. J Pharmacol Exp Ther 2002;300:754-61.

77. Wallace JL, Granger DN. The cellular and molecular basis for gastroduodenal mucosal defense. FASEB J 1996;10:731-40.

78. Silen W, Ito S. Mechanisms for rapid re-epithelialization of the gastric mucosal surface. Annu Rev Physiol 1985;47:217-29.

79. Black BA, Morris GP, Wallace JL. Effects of acid on the basal lamina of the rat stomach and duodenum. Virchows Arch B 1985;50:109-18.

80. Wallace JL, McKnight GW. The mucoid cap over superficial gastric damage in the rat. Gastroenterol 1990;99:295-304.

81. Konturek SJ. Role of epidermal growth factor in gastroprotection and ulcer healing. Scand J Gastroenterol 1988;23:129-233.

82. Tarnawski A, Szabo IL, Husain SS, Soreghan B. Regeneration of gastric mucosa during ulcer healing is triggered by growth factors and signal transduction pathways. J Physiol Paris 2001;95:337-44.

83. Tarnawski A, Stachura J, Durbin T, Sarfeh IJ, Gergely H. Increased expression of epidermal growth factor receptor during gastric ulcer healing in rats. Gastroenterol 1992;102:695-8.

84. Ma L, Elliott SN, Cirino G, Buret A, Ignarro LJ, Wallace JL. Platelets modulate gastric ulcer healing: role of endostatin and vascular endothelial growth factor release. Proc Natl Acad Sci USA 2001;98:6470-5.

85. Mizuno H, Sakamoto C, Matsuda K, et al. Induction of cyclooxygenase 2 in gastric mucosal lesions and its inhibition by the specific antagonist delays healing in mice. Gastroenterol 1997;112:645-8

86. Jones MK, Wang H, Peskar BM, et al. Inhibition of angiogenesis by nonsteroidal anti-inflammatory drugs: insight into mechanisms and implications for cancer growth and ulcer healing. Nat Med 1999;5:1418-23.

87. Schmassmann A. Mechanisms of ulcer healing and effects of nonsteroidal anti-inflammatory drugs. Am J Med 1998;104:43-51S.

88. Stadler P, Armstrong D, Margalith D, et al. Diclofenac delays healing of gastroduodenal mucosal lesions. Double-blind, placebocontrolled endoscopic study in healthy volunteers. Dig Dis Sci 1991;36:594-600.

89. Schmassmann A, Peskar BM, Stettler C, et al. Effects of inhibition of prostaglandin endoperoxide synthase- 2 in chronic gastrointestinal ulcer models in rats. Br J Pharmacol 1998;123:795-804.

90. Ma L, del Soldato P, Wallace JL. Divergent effects of new cyclooxygenase inhibitors on gastric ulcer healing: Shifting the angiogenic balance. Proc Natl Acad Sci USA 2002;99:13243-7.

91. Elliott SN, McKnight W, Cirino G, Wallace JL. A nitric oxidereleasing nonsteroidal anti-inflammatory drug accelerates gastric ulcer healing in rats. Gastroenterol 1995;109:524-30.

92. Bonner GF. Exacerbation of inflammatory bowel disease associated with use of celecoxib. Am J Gastroenterol 2001;96:1306-8.

93. Reuter BK, Cirino G, Wallace JL. Markedly reduced intestinal toxicity of a diclofenac derivative. Life Sci 1994;55:PL1-8. 


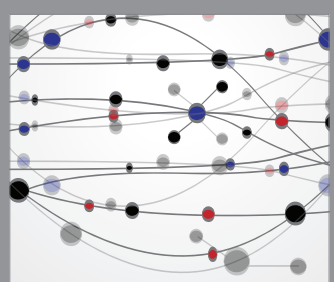

The Scientific World Journal
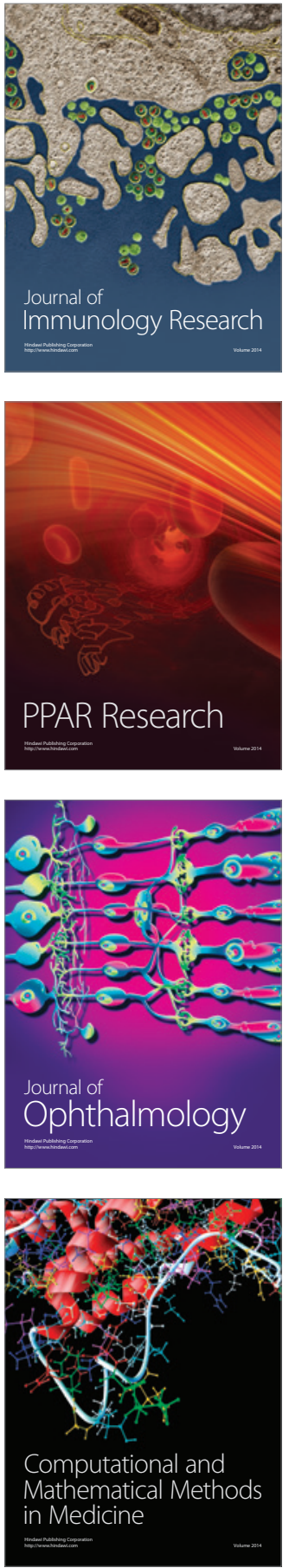

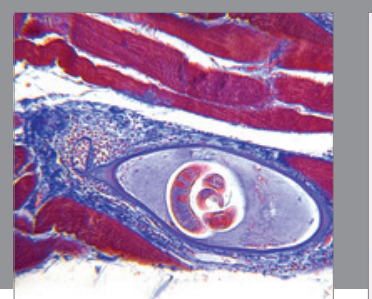

Gastroenterology Research and Practice

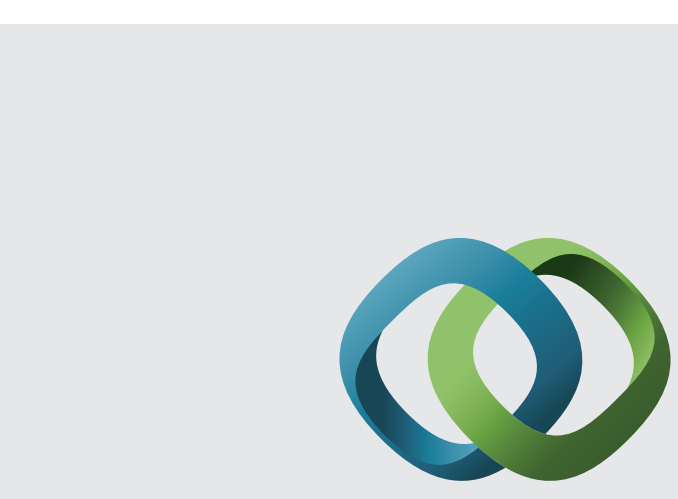

\section{Hindawi}

Submit your manuscripts at

http://www.hindawi.com
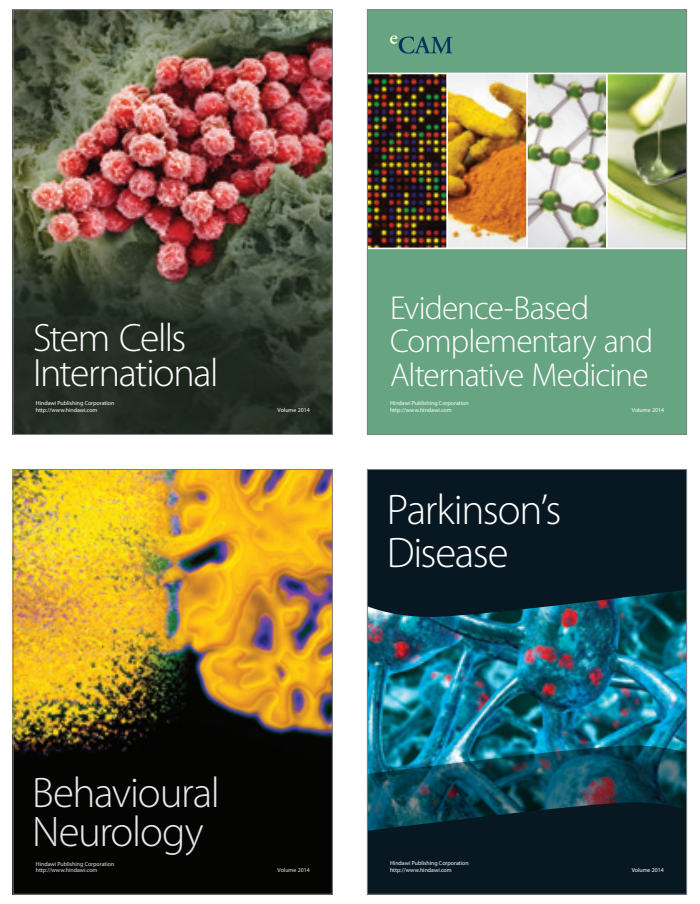
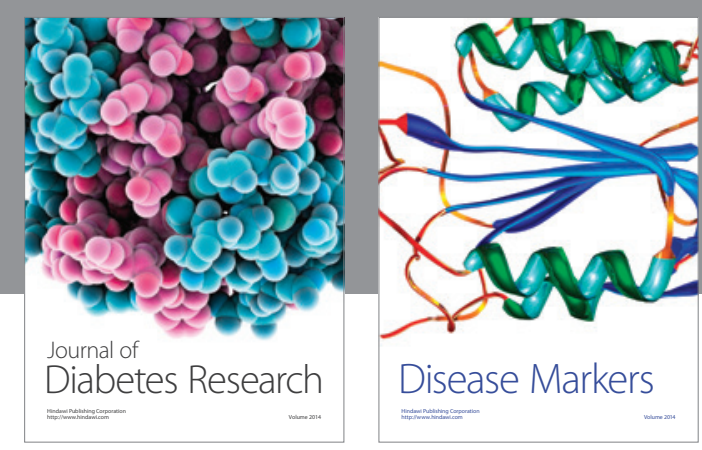

Disease Markers
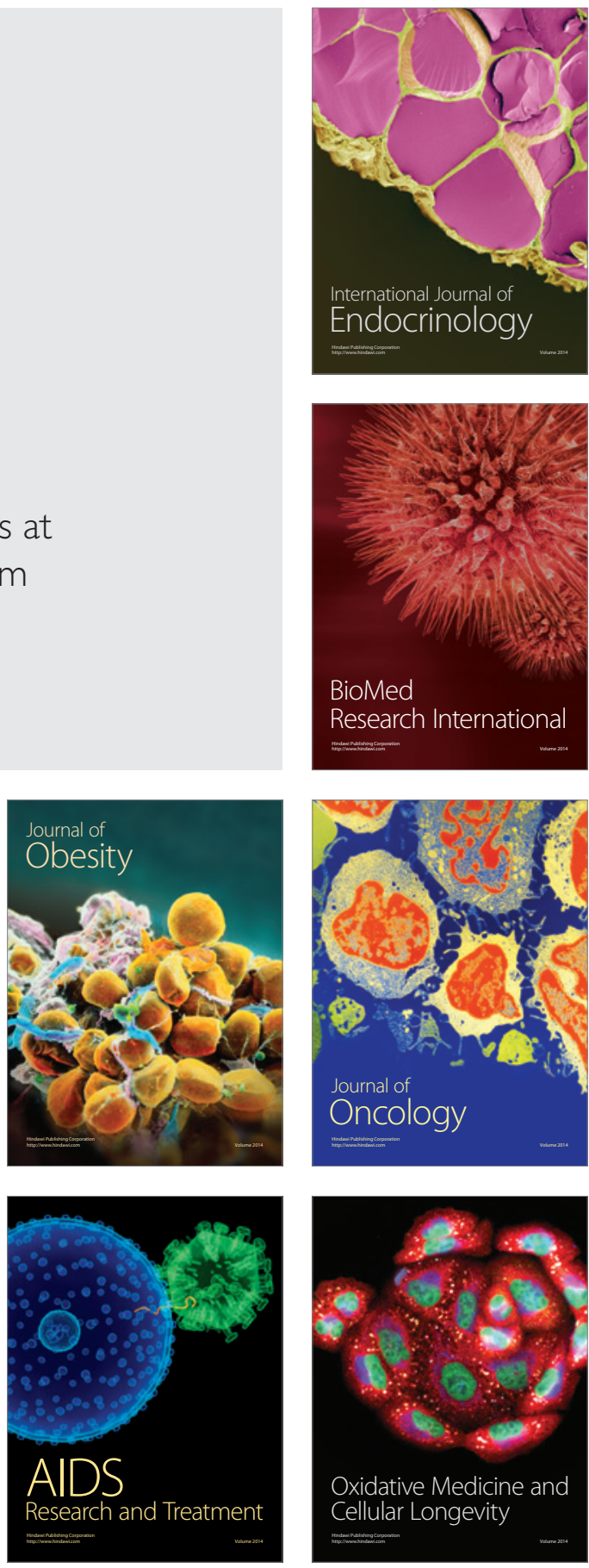